\title{
How Does Bone Strength Compare Across Sex, Site, and Ethnicity?
}

\author{
Stephen H. Schlecht PhD, Erin M. R. Bigelow MS, \\ Karl J. Jepsen PhD
}

Published online: 5 March 2015

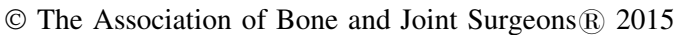

\begin{abstract}
Background The risk of fragility fractures in the United States is approximately 2.5 times greater among black and white women compared with their male counterparts. On average, men of both ethnicities have wider bones of greater cortical mass compared with the narrower bones of lower cortical mass among women. However, it remains uncertain whether the low cortical area observed in the long bones of women is consistent with their narrower bone diameter or if their cortical area is reduced beyond that which is expected for the sex differences in body size and external bone size.

Questions/purposes We asked (1) do black and white women consistently have narrower bones of less strength
\end{abstract}

This work was supported by a grant from the US Department of Defense (W81XWH-09-2-0113) (KJJ) and the National Institutes of Health (AR44927; AR065424) (KJJ).

The opinions or assertions contained herein are the private views of the authors and are not to be construed as official or as reflecting the views of the US Army, the Department of Defense, or the National Institutes of Health.

All ICMJE Conflict of Interest Forms for authors and Clinical Orthopaedics and Related Research ${ }^{\circledR}$ editors and board members are on file with the publication and can be viewed on request.

Clinical Orthopaedics and Related Research ${ }^{\mathbb{R}}$ neither advocates nor endorses the use of any treatment, drug, or device. Readers are encouraged to always seek additional information, including FDAapproval status, of any drug or device prior to clinical use.

This work was performed at the University of Michigan, Ann Arbor, MI, USA, and The Cleveland Museum of Natural History, Cleveland, $\mathrm{OH}$, USA.

S. H. Schlecht ( $\square)$, E. M. R. Bigelow, K. J. Jepsen Department of Orthopaedic Surgery, University of Michigan, 109 Zina Pitcher Place, Room 2148 BSRB, Ann Arbor, MI 48109, USA

e-mail: sschlech@med.umich.edu across long bones compared with black and white men; and (2) do all long bones of black and white women have reduced cortical area compared with black and white men? Methods Peripheral quantitative CT was used to quantify bone strength and cross-sectional morphology from the major long bones of 125 white and 115 black adult men and women (20-35 years of age). Regression analyses were used to test for differences in bone strength and cortical area after for adjusting for either body size, bone size, or both.

Results After adjusting bone strength for body size, regression analyses showed that black women had lower bone strength compared with black men (women: mean = 298.7-25,522 mg HA mm${ }^{4}, 95 \%$ confidence interval [CI], 270-27,692 mg HA mm ${ }^{4}$; men: mean $=381.6-30,945 \mathrm{mg}$ HA mm ${ }^{4}, 95 \%$ CI, 358.2-32,853 mg HA mm${ }^{4}$; percent difference $=12 \%-38 \%, \quad \mathrm{p}=0.06-0.0001)$. Similarly, white women also had lower bone strength compared with white men (women: mean $=229.5-22,892 \mathrm{mg} \mathrm{HA} \mathrm{mm}$, 95\% CI, 209.3-24,539 mg HA mm ; men: mean = 314.3-29,986 mg HA mm 4 , 95\% CI, 297.3-31,331 mg HA mm ${ }^{4}$; percent difference $=27 \%-49 \%, \mathrm{p}=0.0001$ ). All long bones of women for both ethnicities showed lower cortical area compared with men. After accounting for both body size and external bone size, black women (women: mean $=43.25-357.70 \mathrm{~mm}^{2}, 95 \% \mathrm{CI}, 41.45-367.52 \mathrm{~mm}^{2}$; men: mean $=48.06-400.10 \mathrm{~mm}^{2}, 95 \% \mathrm{CI}, 46.67-408.72$; percent difference $=6 \%-25 \%, \quad \mathrm{p}=0.02-0.0001)$ and white women (women: mean $=38.53-350.10 \mathrm{~mm}^{2}, 95 \%$ CI, 36.99-359.80 mm² men: mean $=42.06-394.30 \mathrm{~mm}^{2}$, 95\% CI, 40.95-402.10 $\mathrm{mm}^{2}$; percent difference $=6 \%$ $22 \%, \mathrm{p}=0.02-0.0001)$ were shown to have lower cortical area than their male counterparts. Therefore, the long bones of women are not only more slender than those of men, but also show a reduced cortical area that is $6 \%$ to $25 \%$ greater 
than expected for their external size, depending on the bone being considered.

Conclusions The long bones of females are not just a more slender version of male long bones. Women have less cortical area than expected for their body size and bone size, which in part explains their reduced bone strength when compared with the more robust bones of men.

Clinical Relevance The outcome of this assessment may be clinically important for the development of diagnostics and treatment regimens used to combat fractures. Future work should look at how the relationship among parameters reported here translates to the more fracture-prone metaphyseal regions.

\section{Introduction}

The risk of fragility fractures in the United States is approximately 2.5 times greater among black and white women compared with their male counterparts [3, 13]. Moreover, fracture rates among black women are approximately $50 \%$ less than that of white women, whereas fracture rates among men of both ethnicities are relatively similar [3]. Many have suggested this sex difference in fracture risk, both within and across ethnicities, is predominantly attributable to body size $[8,16,22,23]$ and hormonal differences $[14,24]$. When looking at population averages within both ethnicities, men have wider bones of greater cortical mass compared with women [1, 18, 19, 22]. This knowledge is often used to identify traits that contribute to fracture susceptibility. However, healthy men and women of both ethnicities demonstrate a $30 \%$ to $180 \%$ natural variation in bone strength within each population that warrants further consideration [20]. For example, are the components of a woman's skeleton simply a more slender version of those of a man's skeleton, or are they constructing their bones in entirely different manners? Any inconsistency in the way men and women construct bone would have to be taken into consideration when developing advanced diagnostics for monitoring changes in bone strength with aging as well as developing treatment regimens used to combat fractures.

Previously, we reported that bone strength, whole bone robustness (transverse cross-sectional width relative to bone length), and cortical area significantly covary with one another in a predictable fashion throughout the appendicular skeleton. Those individuals who have slender bones (narrow relative to bone length) demonstrate a lower bone strength and less mass accumulation (ie, cortical area) than individuals who have more robust bones (wide relative to bone length), irrespective of body size. Hence, we established that robustness and cortical area naturally vary in conjunction with the variability in bone strength.
Therefore, these traits can now be used to evaluate whether black and white men and women construct their bones in fundamentally different manners, because these coordinated traits provide a general assessment of whole bone strength and stiffness. Jepsen et al. [10] found that the femora of black and white women accumulate significantly less cortical area for their body size and robustness compared with their male counterparts. We investigate whether this reduction in cortical area among the femora of black and white women is present throughout the appendicular skeleton. The goal of this study is to map out the differences in bone strength and cortical area between men and women for all the major long bones.

We systematically examined the major long bones of the appendicular skeleton in both black and white men and women comprising the Hamman-Todd Osteological Collection. First, we compared bone strength indices between sex cohorts for each ethnicity after adjusting for body size for each individual long bone. Subsequently, we also determined how two components of bone strength, robustness (a reference of external size) and cortical area (a reference of mass accumulation), individually compared between sex groups within each ethnicity for each individual long bone. Using these variables we asked the following questions: (1) do black and white women consistently have narrower bones of less strength across long bones compared with black and white men; and (2) do all long bones of black and white women have reduced cortical area compared with black and white men?

\section{Materials and Methods}

To evaluate whether men and women of both ethnicities construct all long bones in different ways, we examined the left femur, tibia, humerus, radius, second metacarpal, and third metacarpal from the skeletal remains of individuals comprising the Hamann-Todd Osteological Collection curated at the Cleveland Museum of Natural History (Cleveland, OH, USA). The sample population we used for our assessments included individuals between the ages of 20 and 35 years and consisted of 63 black men, 52 black women, 74 white men, and 52 white women. Body weight was measured at the time of autopsy.

Data quantification methods were described by us previously [21]. Briefly, slice images were captured using peripheral quantitative CT (XCT 2000; Stratec Medizentechnik, Pforzheim, Germany) at a $0.10 \mathrm{~mm} \times 0.10-\mathrm{mm}$ in-plane pixel size from the $50 \%$ middiaphysis of each bone. Data quantified from each image included total area, cortical area, mean gray value, and the rectangular moments of inertia about the anterioposterior $\left(\mathrm{I}_{\mathrm{AP}}\right)$ and mediolateral $\left(\mathrm{I}_{\mathrm{ML}}\right)$ axes. After measuring bone length, the 
cross-sectional images were used to calculate robustness (total area/bone length). Cortical tissue mineral density for each bone was calculated using the mean gray value and calibration constants derived from daily scans of a standard phantom. This value was then used to estimate whole bone bending stiffness and strength, or a bone strength index, by multiplying tissue mineral density by $\mathrm{I}_{\mathrm{ML}}$. The estimation of tissue mineral density was previously validated in our laboratory by measuring ash content and cortical porosity [11], and the bone strength index was previously validated by us with four-point bending of cadaveric long bones [20].

Minitab 16.1.1 (Minitab Inc, State College, PA, USA) and Prism 6 (GraphPad Software Inc, La Jolla, CA, USA) were used for all statistical analyses. All data was normally distributed ( $p>0.05$, Kolmogorov-Smirnov test), enabling the use of parametric tests. Linear regression analyses were performed to determine whether all long bones of men and women of both ethnicities were constructed in fundamentally different ways. First, the slopes and y-intercepts of a series of regressions among bone strength index, robustness, and body size of men and women were compared through an analysis of covariance (ANCOVA) to determine whether men consistently build stronger and wider bones throughout their skeleton. Second, the slope and y-intercepts of a series of regressions among robustness, and cortical area, all adjusted for body size, were compared using ANCOVA to determine whether all long bones for women demonstrate the same reduced cortical area previously reported for the femur [10]. Third, a general linear model (GLM) was performed to compare group mean differences in bone strength between men and women. To compare bone strength and robustness, body size was included as a covariate, and to compare cortical area, both body size and robustness were included as covariates because cortical area naturally correlates positively with robustness.

\section{Results}

The bone strength index of all bones analyzed increased in conjunction with body size in both white and black men and women. Black women showed a significantly reduced y-intercept for all bones compared with black men (women: $\quad y$-intercept $=116.3-1273 \mathrm{~mm}^{4} \quad \mathrm{mg} \quad \mathrm{HA}, \quad 95 \%$ confidence interval $[\mathrm{CI}],-8.484$ to $12,211 \mathrm{~mm}^{4} \mathrm{mg} \mathrm{HA}$; men: $y$-intercept $=130.5-9768 \mathrm{~mm}^{4} \mathrm{mg} \mathrm{HA}, 95 \% \mathrm{CI}$, -7679 to 22,$352 ; p=0.0001-0.06$, ANCOVA). Thus, the sex-specific difference in bone strength did not deviate across the population. However, when comparing whites, there was a significant difference in slope between men and women for all bones (women: slope $=1.3-33.3 \mathrm{~mm}^{4} \mathrm{mg}$ $\mathrm{HA} / \mathrm{kg} \mathrm{cm}, 95 \% \mathrm{CI},-0.4$ to $59.2 \mathrm{~mm}^{4} \mathrm{mg} \mathrm{HA} / \mathrm{kg} \mathrm{cm}$; men: slope $=5.2-93.1 \mathrm{~mm}^{4} \mathrm{mg} \mathrm{HA} / \mathrm{kg} \mathrm{cm}, 95 \% \mathrm{CI}, 3.2-$ $121.7 \mathrm{~mm}^{4} \mathrm{mg} \mathrm{HA} / \mathrm{kg} \mathrm{cm} ; \mathrm{p}=0.004-0.05$, ANCOVA). This suggests that the relationship between bone strength and body size is more similar among the smaller white men and women compared with those who are larger, where more divergence occurs. GLM-derived group mean differences demonstrated that all bones of black women had lower bone strength (women: mean $=298.7-25,522 \mathrm{mg}$ HA mm ${ }^{4}, 95 \%$ CI, 270-27,692 mg HA mm${ }^{4}$; men: mean $=381.6-30,945 \mathrm{mg}$ HA $\mathrm{mm}^{4}$, 95\% CI, 358.2 $32,853 \mathrm{mg} \mathrm{HA} \mathrm{mm}{ }^{4}$; percent difference $=12 \%-38 \%$, $\mathrm{p}=0.06-0.0001, \mathrm{GLM})$, relative to body size, than black men (Table 1). Similarly, white women also demonstrated lower bone strength (women: mean $=229.5-22,892 \mathrm{mg}$ HA mm ${ }^{4}, 95 \%$ CI, 209.3-24,539 mg HA mm${ }^{4}$; men: mean $=314.3-29,986 \mathrm{mg}$ HA mm${ }^{4}$, 95\% CI, 297.3$31,331 \mathrm{mg} \mathrm{HA} \mathrm{mm}{ }^{4}$; percent difference $=27 \%-49 \%$, $\mathrm{p}=0.0001, \mathrm{GLM})$ for all skeletal elements compared with white men (Table 1). However, when adjusting for both robustness and body size, these sex-specific differences in bone strength were reduced with black women only demonstrating a significant difference in the femora (women: mean $=27,127 \mathrm{mg} \mathrm{HA} \mathrm{mm}{ }^{4}, 95 \% \mathrm{CI}, 25,687-28,386 \mathrm{mg}$ HA mm${ }^{4}$; men: mean $=29,620 \mathrm{mg} \mathrm{HA} \mathrm{mm}, 95 \% \mathrm{CI}$, 28,514-30,725 mg HA mm${ }^{4}$; percent difference $=9 \%$, $\mathrm{p}=0.01, \mathrm{GLM}$ ) and humeri (women: mean $=8322 \mathrm{mg} \mathrm{HA}$ $\mathrm{mm}^{4}, 95 \%$ CI, 7902-9741 mg HA mm${ }^{4}$; men: mean $=$ 9627 mg HA mm ${ }^{4}, 95 \%$ CI, 9260-9993 mg HA mm ${ }^{4}$; percent difference $=15 \%, \mathrm{p}=0.0002$, GLM) and white women demonstrating a significant difference in the femora (women: mean $=25,288 \mathrm{mg} \mathrm{HA} \mathrm{mm}{ }^{4}, 95 \% \mathrm{CI}, 24,093-$ $26,482 \mathrm{mg} \mathrm{HA} \mathrm{mm}{ }^{4}$; men: mean $=28,302 \mathrm{mg} \mathrm{HA} \mathrm{mm}$, 95\% CI, 27,340-29,263 mg HA mm ; percent difference $=11 \%, \mathrm{p}=0.0007$, GLM), tibiae (women: mean $=$ $12,876 \mathrm{mg} \mathrm{HA} \mathrm{mm}{ }^{4}, 95 \%$ CI, $12,149-13,602 \mathrm{mg} \mathrm{HA} \mathrm{mm}^{4}$; men: mean $=14,352 \mathrm{mg}$ HA mm${ }^{4}, 95 \%$ CI, $13,757-$ $14,946 \mathrm{mg} \mathrm{HA} \mathrm{mm}^{4}$; percent difference $=11 \%, \mathrm{p}=0.006$, GLM), humeri (women: mean $=6756 \mathrm{mg} \mathrm{HA} \mathrm{mm}^{4}, 95 \% \mathrm{CI}$, 6365-7146 mg HA mm ${ }^{4}$; men: mean $=8081 \mathrm{mg} \mathrm{HA} \mathrm{mm}{ }^{4}$, 95\% CI, 7770-8391 mg HA mm ${ }^{4}$; percent difference $=18 \%$, $\mathrm{p}=0.0001$, GLM), and third metacarpi (women: mean $=$ $265.7 \mathrm{mg} \mathrm{HA} \mathrm{mm}{ }^{4}, 95 \% \mathrm{CI}, 247.4-283.9 \mathrm{mg} \mathrm{HA} \mathrm{mm}{ }^{4}$; men: mean $=291.7 \mathrm{mg} \mathrm{HA} \mathrm{mm}{ }^{4}, 95 \%$ CI, $277.1-306.2 \mathrm{mg}$ HA $\mathrm{mm}^{4}$; percent difference $=9 \%, \mathrm{p}=0.05$, GLM) (Fig. 1). Therefore, the natural variation in robustness accounted for approximately two-thirds of the body size adjusted differences in bone strength between men and women.

Robustness also increased with body size for all long bones. Women had consistently more slender bones (narrow relative to length) compared with men for both blacks (women: $y$-intercept $=0.43-0.94 \mathrm{~mm} / \mathrm{kg} \mathrm{cm}, 95 \%$ CI, $0.28-1.18 \mathrm{~mm} / \mathrm{kg} \mathrm{cm}$; men: y-intercept $=0.52-1.04 \mathrm{~mm} /$ 
Table 1. Bone strength index sex differences adjusted for body size*

\begin{tabular}{|c|c|c|c|c|c|c|c|c|c|c|}
\hline \multirow[t]{3}{*}{ Bone } & \multicolumn{10}{|l|}{ Whites } \\
\hline & \multicolumn{4}{|c|}{ Males $(n=74)$} & \multicolumn{4}{|c|}{ Females $(\mathrm{n}=52)$} & \multicolumn{2}{|c|}{ Percent difference } \\
\hline & $\bar{x}$ & $\sigma$ & Lower CI & Upper CI & $\bar{x}$ & $\sigma$ & Lower CI & Upper CI & Male $>$ female & $\mathrm{p}$ value \\
\hline Femora & 29,986 & 5905 & 28,640 & 31,331 & 22,892 & 6062 & 21,244 & 24,539 & 27 & 0.0001 \\
\hline Tibiae & 15,251 & 3551 & 14,441 & 16,060 & 11,631 & 3596 & 10,653 & 12,608 & 27 & 0.0001 \\
\hline Humeri & 8983 & 2238 & 8473 & 9492 & 5472 & 2310 & 4844 & 6099 & 49 & 0.0001 \\
\hline Radii & 2006 & 559. & 1878 & 2133 & 1345 & 585 & 1185 & 1504 & 39 & 0.0001 \\
\hline Second metacarpi & 318.6 & 71.7 & 302.2 & 334.9 & 229.5 & 74.1 & 209.3 & 249.6 & 33 & 0.0001 \\
\hline Third metacarpi & 314.3 & 74.3 & 297.3 & 331.2 & 232.2 & 76.6 & 211.3 & 253.0 & 30 & 0.0001 \\
\hline \multirow[t]{3}{*}{ Bone } & \multicolumn{10}{|l|}{ Blacks } \\
\hline & \multicolumn{4}{|c|}{ Males $(n=63)$} & \multicolumn{4}{|c|}{ Females $(\mathrm{n}=52)$} & \multicolumn{2}{|c|}{ Percent difference } \\
\hline & $\bar{x}$ & $\sigma$ & Lower CI & Upper CI & $\bar{x}$ & $\sigma$ & Lower CI & Upper CI & Male $>$ female & $\mathrm{p}$ value \\
\hline Femora & 30,945 & 7727 & 29,036 & 32,853 & 25,522 & 7987 & 23,351 & 27,692 & 19 & 0.002 \\
\hline Tibiae & 19,475 & 5266 & 18,174 & 20,775 & 17,299 & 5585 & 15,780 & 18,817 & 12 & 0.06 \\
\hline Humeri & 10,559 & 2813 & 9864 & 1253 & 7193 & 2914 & 6400 & 7985 & 38 & 0.0001 \\
\hline Radii & 2446 & 727 & 2266 & 2625 & 1678 & 746 & 1475 & 1880 & 37 & 0.0001 \\
\hline Second metacarpi & 381.6 & 94.4 & 358.2 & 404.9 & 302 & 98 & 275 & 328 & 23 & 0.0002 \\
\hline Third metacarpi & 391.1 & 100.9 & 366.1 & 416.0 & 298.7 & 105.4 & 227.0 & 327.3 & 27 & 0.0001 \\
\hline
\end{tabular}

* Mean, SD, and the upper and lower confidence intervals (CIs) are given for each skeletal element along with the percent difference between means of males and females and the actual $\mathrm{p}$ values.

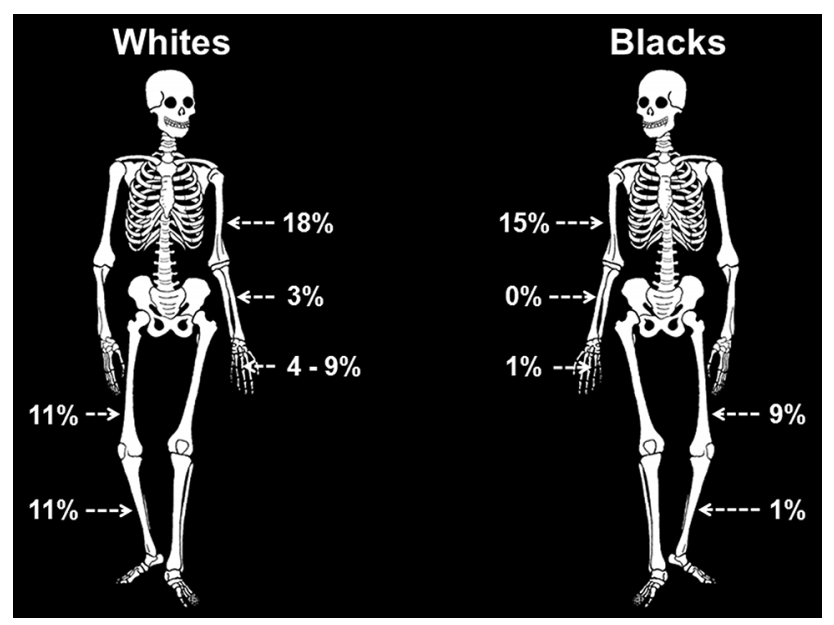

Fig. 1 Schematic mapping out the sex differences in the bone strength index for blacks and whites. Percentages reflect the degree of reduced bone strength among women in comparison to men.

$\mathrm{kg} \mathrm{cm}, 95 \% \mathrm{CI}, 0.41-1.26 \mathrm{~mm} / \mathrm{kg} \mathrm{cm}, \mathrm{p}=0.04-0.0001$, ANCOVA) and whites (women: $y$-intercept $=$ $0.43-1.03 \mathrm{~mm} / \mathrm{kg} \mathrm{cm}, \quad 95 \%$ CI, $0.35-1.22 \mathrm{~mm} / \mathrm{kg} \mathrm{cm}$; men: $y$-intercept $=0.40-1.04 \mathrm{~mm} / \mathrm{kg} \mathrm{cm}, 95 \% \mathrm{CI}, 0.32$ $1.22 \mathrm{~mm} / \mathrm{kg} \mathrm{cm} ; \mathrm{p}=0.0001$, ANCOVA). This was uniform across both ethnicities. Group mean differences in robustness after accounting for body size showed that women had significantly more slender bones compared with men for both blacks (women: mean $=0.46-1.20 \mathrm{~mm}$, 95\% CI, $0.43-1.24 \mathrm{~mm}$; men: mean $=0.55-1.27 \mathrm{~mm}$, 95\% CI, 0.53-1.31; percent difference $=6 \%-19 \%$, $\mathrm{p}=0.04-0.0001$, GLM) and whites (women: mean $=$ $0.44-1.18 \mathrm{~mm}, 95 \% \mathrm{CI}, 0.42-1.21 \mathrm{~mm}$; men: mean $=$ $0.52-1.30 \mathrm{~mm}, 95 \% \mathrm{CI}, 0.51-1.33 \mathrm{~mm}$; percent difference $=9 \%-21 \%, \mathrm{p}=0.0001, \mathrm{GLM})$ (Table 2). The sexspecific difference in robustness was two times greater among the upper long bones in both black (14\%-19\%) and white (17\%-21\%) women compared with the lower long bones of black (6\%-7\%) and white (9\%-10\%) women.

All long bones of women for both ethnicities demonstrated lower cortical area compared with men (Fig. 2). Because this relationship is characteristic of slender bones, we tested whether the sex-specific differences observed in this population are at the degree expected for the differences in robustness. Group mean differences for cortical area, after accounting for both robustness and body size, revealed that women's long bones had significantly lower cortical area compared with men among both blacks (women: mean $=43.25-357.70 \mathrm{~mm}^{2}$, 95\% CI, 41.45$367.52 \mathrm{~mm}^{2}$; men: mean $=48.06-400.10 \mathrm{~mm}^{2}, 95 \% \mathrm{CI}$, $46.67-408.72$; percent difference $=6 \%-25 \%, \mathrm{p}=0.02$ 0.0001 , GLM) and whites (women: mean $=38.53$ 
Table 2. Robustness sex differences adjusted for body size*

\begin{tabular}{|c|c|c|c|c|c|c|c|c|c|c|}
\hline \multirow[t]{3}{*}{ Bone } & \multicolumn{10}{|c|}{ Whites } \\
\hline & \multicolumn{4}{|c|}{ Males $(\mathrm{n}=74)$} & \multicolumn{4}{|c|}{ Females $(\mathrm{n}=52)$} & \multicolumn{2}{|c|}{ Percent difference } \\
\hline & $\bar{x}$ & $\sigma$ & Lower CI & Upper CI & $\bar{x}$ & $\sigma$ & Lower CI & Upper CI & Male $>$ female & $\mathrm{p}$ value \\
\hline Femora & 1.30 & 0.12 & 1.27 & 1.33 & 1.18 & 0.13 & 1.14 & 1.21 & 10 & 0.0001 \\
\hline Tibiae & 1.19 & 0.12 & 1.16 & 1.22 & 1.08 & 0.12 & 1.05 & 1.12 & 9 & 0.0001 \\
\hline Humeri & 0.99 & 0.13 & 0.96 & 1.02 & 0.83 & 0.13 & 0.79 & 0.87 & 17 & 0.0001 \\
\hline Radii & 0.52 & 0.06 & 0.51 & 0.54 & 0.44 & 0.07 & 0.42 & 0.46 & 18 & 0.0001 \\
\hline Second metacarpi & 0.88 & 0.09 & 0.86 & 0.90 & 0.47 & 0.09 & 0.72 & 0.77 & 17 & 0.0001 \\
\hline Third metacarpi & 0.95 & 0.14 & 0.92 & 0.99 & 0.77 & 0.15 & 0.73 & 0.81 & 21 & 0.0001 \\
\hline \multirow[t]{3}{*}{ Bone } & \multicolumn{10}{|c|}{ Blacks } \\
\hline & \multicolumn{4}{|c|}{ Males $(n=63)$} & \multicolumn{4}{|c|}{ Females $(\mathrm{n}=52)$} & \multicolumn{2}{|c|}{ Percent difference } \\
\hline & $\bar{x}$ & $\sigma$ & Lower CI & Upper CI & $\bar{x}$ & $\sigma$ & Lower CI & Upper CI & Male $>$ female & $\mathrm{p}$ value \\
\hline Femora & 1.27 & 0.15 & 1.23 & 1.31 & 1.20 & 0.16 & 1.16 & 1.24 & 6 & 0.04 \\
\hline Tibiae & 1.25 & 0.16 & 1.21 & 1.29 & 1.17 & 0.17 & 1.12 & 1.22 & 7 & 0.02 \\
\hline Humeri & 1.04 & 0.16 & 1.00 & 1.08 & 0.90 & 0.16 & 0.86 & 0.95 & 14 & 0.0002 \\
\hline Radii & 0.55 & 0.07 & 0.53 & 0.57 & 0.46 & 0.08 & 0.43 & 0.48 & 19 & 0.0001 \\
\hline Second metacarpi & 0.91 & 0.11 & 0.88 & 0.94 & 0.79 & 0.12 & 0.75 & 0.82 & 15 & 0.0001 \\
\hline Third metacarpi & 0.92 & 0.12 & 0.89 & 0.78 & 0.81 & 0.12 & 0.78 & 0.85 & 16 & 0.0001 \\
\hline
\end{tabular}

* Mean, SD, and the upper and lower confidence intervals (CIs) are given for each skeletal element along with the percent difference between means of males and females and the actual $\mathrm{p}$ values.

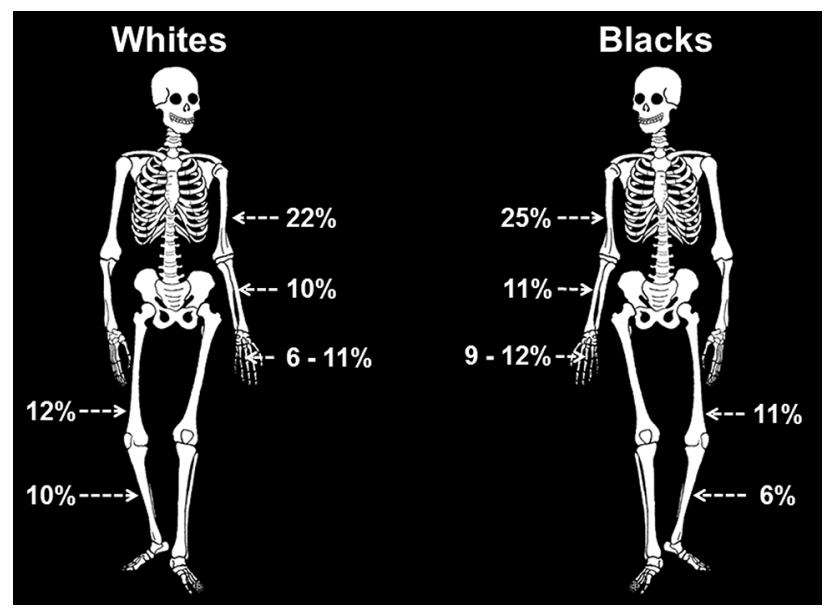

Fig. 2 Schematic mapping out the sex differences in cortical area for blacks and whites. Percentages reflect the degree of reduced bone strength among women in comparison to men.

$350.10 \mathrm{~mm}^{2}, 95 \% \mathrm{CI}, 36.99-359.80 \mathrm{~mm}^{2}$; men: mean $=$ 42.06-394.30 mm², 95\% CI, 40.95-402.10 $\mathrm{mm}^{2}$; percent difference $=6 \%-22 \%, \mathrm{p}=0.02-0.0001$, GLM) (Table 3). The humeri demonstrated the greatest divergence between men and women with a $25 \%$ lower cortical area among blacks and a $22 \%$ lower cortical area among whites
(Fig. 3A-B). This analysis revealed that not only are all long bones more slender for women compared with men, but all long bones of women also show a reduced cortical area that is $6 \%$ to $25 \%$ greater than expected for their robustness, depending on the bone being considered.

\section{Discussion}

The purpose of this study was to map sex-specific differences in bone strength, robustness, and cortical area across the major long bones for black and white men and women. Previously, we showed that men and women of both ethnicities demonstrated natural variation in the manner to which robustness, cortical area, and tissue mineral density are associated with one another across long bones [11, 12, $20,21]$. Slender bones are $30 \%$ to $180 \%$ less stiff and strong than robust bones, relative to body size, with a lower bone strength index, narrower diameter, and lower cortical area [20]. Thus, there would appear to be a biological constraint in the level to which cellular processes (eg, osteoclastic/osteoblastic-driven modeling and remodeling) can be adjusted to mechanically compensate for the natural variation in robustness. It is well known that women tend to have more slender bones than men for a given body size [1, $18,19,22]$, putting them at greater risk of fracturing under 
Table 3. Cortical area adjusted for body size and robustness*

\begin{tabular}{|c|c|c|c|c|c|c|c|c|c|c|}
\hline \multirow[t]{3}{*}{ Bone } & \multicolumn{10}{|l|}{ Whites } \\
\hline & \multicolumn{4}{|c|}{ Males $(\mathrm{n}=74)$} & \multicolumn{4}{|c|}{ Females $(\mathrm{n}=52)$} & \multicolumn{2}{|c|}{ Percent difference } \\
\hline & $\bar{x}$ & $\sigma$ & Lower CI & Upper CI & $\bar{x}$ & $\sigma$ & Lower CI & Upper CI & Male $>$ female & $\mathrm{p}$ value \\
\hline Femora & 394.30 & 34.27 & 386.49 & 402.10 & 350.10 & 35.69 & 340.39 & 359.80 & 12 & 0.0001 \\
\hline Tibiae & 288.40 & 38.09 & 279.71 & 297.08 & 259.80 & 26.14 & 252.69 & 266.90 & 10 & 0.0001 \\
\hline Humeri & 212.20 & 28.28 & 205.75 & 218.64 & 169.70 & 29.81 & 161.59 & 177.80 & 22 & 0.0001 \\
\hline Radii & 93.45 & 7.97 & 91.63 & 95.26 & 84.84 & 8.54 & 82.51 & 87.16 & 10 & 0.0001 \\
\hline Second metacarpi & 42.06 & 4.87 & 40.95 & 43.16 & 39.57 & 5.19 & 38.15 & 40.98 & 6 & 0.02 \\
\hline Third metacarpi & 42.82 & 5.34 & 41.60 & 44.03 & 38.53 & 5.64 & 36.99 & 40.06 & 11 & 0.0002 \\
\hline \multirow[t]{3}{*}{ Bone } & \multicolumn{10}{|l|}{ Blacks } \\
\hline & \multicolumn{4}{|c|}{ Males $(\mathrm{n}=74)$} & \multicolumn{4}{|c|}{ Females $(\mathrm{n}=52)$} & \multicolumn{2}{|c|}{ Percent difference } \\
\hline & $\bar{x}$ & $\sigma$ & Lower CI & Upper CI & $\bar{x}$ & $\sigma$ & Lower CI & Upper CI & Male $>$ female & $\mathrm{p}$ value \\
\hline Femora & 400.10 & 34.92 & 391.47 & 408.72 & 357.70 & 36.14 & 347.87 & 367.52 & 11 & 0.0001 \\
\hline Tibiae & 316.80 & 37.13 & 307.62 & 325.97 & 296.90 & 39.48 & 286.16 & 307.63 & 6 & 0.02 \\
\hline Humeri & 242.30 & 25.45 & 236.01 & 248.58 & 187.80 & 26.49 & 180.59 & 195.00 & 25 & 0.0001 \\
\hline Radii & 106.49 & 10.60 & 103.87 & 109.10 & 95.10 & 10.97 & 92.11 & 98.08 & 11 & 0.0001 \\
\hline Second metacarpi & 48.06 & 5.60 & 46.67 & 49.44 & 44.01 & 5.90 & 42.40 & 45.61 & 9 & 0.002 \\
\hline Third metacarpi & 48.98 & 6.25 & 47.43 & 50.52 & 43.25 & 6.60 & 41.45 & 45.04 & 12 & 0.0001 \\
\hline
\end{tabular}

* Mean, SD, and the upper and lower confidence intervals (CIs) are given for each skeletal element along with the percent difference between means of males and females and the actual $\mathrm{p}$ values.
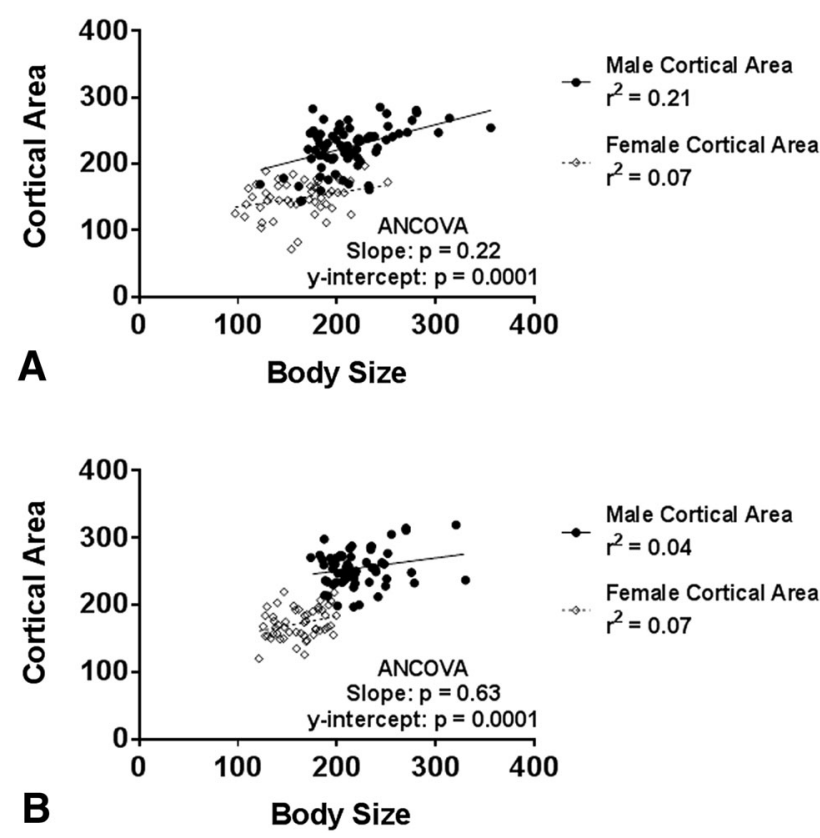

Fig. 3A-B Linear regression plots of the humeri for both ethnicities between cortical area and body size, highlighting the large sex difference we observed. (A) White humeri and (B) black humeri.

extreme loading conditions (eg, military training and falls among the elderly) $[1,11,12,17]$. However, it had yet to be determined whether this difference in strength is the result of fundamental differences in the manner by which men and women construct bone. Mapping the sex-specific differences in skeletal traits for all the long bones confirmed what we reported for the femur in our companion manuscript [10], that women's bones are not merely a more slender version of men's, but that women also have significantly less bone mass (cortical area) than expected for their slenderness. This leads to an even greater structural deficit than expected that may functionally impact how well their bones can resist potentially catastrophic mechanical loads. This inconsistency in the way men and women construct bone should be taken into consideration when developing advanced diagnostics for monitoring changes in bone strength with aging.

One limitation of this study is that the sample cohort is limited to individuals who died approximately 70 to 90 years ago. Therefore, it is possible that there may be environmental affects (eg, activity patterns and nutrition) impacting bone growth and development that may differ between this archived cohort and modern populations. However, in prior work we compared our findings from this anatomical collection with that of modern, healthy military recruits in terms of tibial robustness and cortical area and found no significant differences between the two cohorts. This suggests that despite the potential for differing environmental influences that may exist in our current sample, it has not greatly impacted the parameters 
we included in this study. A second limitation of this study is that the individuals included in our sample were between 20 and 35 years of age. However, we took this approach to provide a foundation for future work focused on how the lower cortical area accumulated during growth for women impacts skeletal aging. For example, further investigations that can be incorporated into clinical studies is whether there are dynamics that impair periosteal expansion in women outside what is expected for slenderness and the associated lower cortical mass. The third limitation is that we only characterized this structural deficit in the diaphysis. However, we previously showed that the corticocancellous region of the femoral neck demonstrates similar trait interactions between external size and cortical mass [7]. Therefore, for future work we will conduct similar studies on the more clinically relevant fractureprone metaphyseal regions of the spine, distal radius, and proximal femur.

Do black and white women consistently have less bone strength across long bones compared with black and white men? The answer is yes. Our analysis showed that black women had a $12 \%$ to $38 \%$ lower bone strength index and white women had a $27 \%$ to $49 \%$ lower bone strength index compared with their respective male counterparts. For black women, this reduction in strength was independent of body size because linear regressions between bone morphology and body size demonstrated no significant difference in slope. However, there was a significant difference in slope between white women and men, which suggests for this ethnicity body size plays a role in the sexspecific difference observed in bone strength. On average, women have more slender bones than men in both ethnicities, which can partially explain the large differences observed in bone strength when compared with men. However, that robustness differences between men and women of both ethnic cohorts only accounted for twothirds the differences in bone strength suggests women were still unable to sufficiently adjust other traits for their slender diameter bones.

Do all long bones of black and white women have reduced cortical area compared with black and white men? The answer is yes. Women showed less cortical mass accumulation in all long bones tested compared with their male counterparts. This range was similar between ethnicities with black women showing a $6 \%$ to $25 \%$ reduction in cortical area and white women showing a $6 \%$ to $22 \%$ reduction compared with black and white men, respectively. The structural deficit observed in mass accumulation was independent of locomotive and gravitational weightbearing loads. The upper and lower long bones of women display a similar deficit in bone mass aside from the humerus, suggesting that at least some of this phenomenon is independent of environmental factors (eg, mechanical load). However, the observation that the lower limbs are less sexually dimorphic in terms of robustness compared with the upper limbs would suggest that the natural variation present in the femora and tibiae is more constrained, in part because of the larger load demand placed on them. The humeri of black and white women showed more than a twofold deficit in cortical area for a given robustness and body size compared with the femora and tibiae, which are traditionally viewed as handling the brunt of weightbearing activity. Finding that the humerus of women had the greatest deficit in bone mass is intriguing, particularly because the risk of fracturing their proximal humerus is five times greater among women 60 to 64 years of age and 21 times greater among women 80 to 84 years of age with approximately $70 \%$ of all proximal humeral fracture visits to the emergency department being made by women [15]. However, it is unknown how our finding of a dramatic cortical area deficit in the diaphysis translates to the fracture-prone metaphyseal region. When comparing sexspecific differences between ethnicities, the relationship among traits differed uniformly among black men and women. The relationship between external bone size and mass accumulation, when accounting for body size, was not uniform among many of the long bones of whites. Thus, it appears that white women with larger body sizes build bones that are narrower and weaker in comparison to their male counterparts of similar body size. Therefore, these women would be at an even greater risk of fracturing than other women within the population because their bones would be even weaker as a result of a wider and thinner cortex [2]. Lastly, it is important to note that although black women showed a large reduction in cortical mass, this finding is not consistent with the reports that black women present with approximately $50 \%$ less bone fractures than that of white women [3]. Moreover, clinical data have found that black women are not significantly at a greater risk of fracture compared with black men $[3,6]$. This disagreement between our data and that of modern clinical meta-analyses may be that the sex differences in cortical mass we observed in the long bone diaphysis do not translate to the more fracture-prone metaphyseal regions for this ethnic group. Therefore, future work should seek to resolve this discrepancy by applying our methodologies reported here to the proximal femur and distal radius.

Finding that women accumulate less bone mass than expected for their body size and robustness throughout their appendicular skeleton suggests that sex-specific biological differences also translate to the skeletal level, impacting the manner in which bone mass is acquired and maintained. However, we must first establish a similar interaction among traits in the metaphyseal regions to investigate whether these structures demonstrate a similar 
deficit in mass. If future work shows that this deficit is also apparent within these fracture-prone regions, then sexspecific diagnoses and treatments may be required to more effectively combat fragility fractures. Regardless of the outcomes of future studies, finding these sex-specific differences in the diaphysis highlights the need for better designed basic, translational, and clinical studies that not only address the root causes, diagnoses, and treatments of fragility fractures in one sex, but also investigate how these aspects relate to the other sex [4, 5, 9].

Acknowledgments We thank the Glancy Family for their support of this research. We also thank the Cleveland Museum of Natural History, Dr Yohannes Haile-Selassie, and Lyman Jellema for access to, and assistance with, the Hamann-Todd Osteological Collection and Lauren Smith, Dan Schiferl, and Charles Roehm for their helpful comments and technical support.

\section{References}

1. Beck TJ, Ruff CB, Shaffer RA, Betsinger K, Trone DW, Brodine SK. Stress fracture in military recruits: gender differences in muscle and bone susceptibility factors. Bone. 2000;27:437-444.

2. Bjornerem A, Bui QM, Ghasem-Zadeh A, Hopper JL, Zebaze R, Seeman E. Fracture risk and height: an association partly accounted for by cortical porosity of relatively thinner cortices. $J$ Bone Miner Res. 2013;28:2017-2026.

3. Cauley JA. Defining ethnic and racial differences in osteoporosis and fragility fractures. Clin Orthop Relat Res. 2011;469: 1891-1899.

4. Clayton JA, Collins FS. Policy: NIH to balance sex in cell and animal studies. Nature. 2014;509:282-283.

5. Clayton JA, Joseph S. Why research sex differences and similarities? Med Phys. 2013;40:1-2.

6. Cummings SR, Melton LJ. Epidemiology and outcomes of osteoporotic fractures. Lancet. 2002;359:1761-1767.

7. Epelboym Y, Gendron RN, Mayer J, Fusco J, Nasser P, Gross G, Ghillani R, Jepsen KJ. The interindividual variation in femoral neck width is associated with the acquisition of predictable sets of morphological and tissue-quality traits and differential bone loss patterns. J Bone Miner Res. 2012;27:1501-1510.

8. Gilsanz V, Skaggs DL, Kovanlikaya A, Sayre J, Luiza Loro M, Kaufman F, Korenman SG. Differential effect of race on the axial and appendicular skeletons of children. J Clin Endocrinol Metab. 1998;83:1420-1427.

9. Hammes SR. Sex matters in preclinical research. Mol Endocrinol. 2014;28:1209-1210.
10. Jepsen KJ, Bigelow EMR, Schlecht SH. Women build long bones with less cortical mass relative to body size and bone sixe compared to men. Clin Orthop Relat Res. 2015 Feb 18 [Epub ahead of print].

11. Jepsen KJ, Centi A, Duarte GF, Galloway K, Goldman H, Hampson N, Lappe JM, Cullen DM, Greeves J, Izard R, Nindl BC, Kraemer WJ, Negus CH, Evans RK. Biological constraints that limit compensation of a common skeletal trait variant lead to inequivalence of tibial function among healthy young adults. $J$ Bone Miner Res. 2011;26:2872-2885.

12. Jepsen KJ, Evans EJ, Negus CH, Gagnier JJ, Centi A, Erlich T, Hadid A, Yanovich R, Moran DS. Variation in tibial functionality and fracture susceptibility among healthy, young adults arises from the acquisition of biologically distinct sets of traits. $J$ Bone Miner Res. 2013;28:1290-1300.

13. Kanis JA, Johnell O, De Laet C, Jonsson B, Oden A, Ogelsby AK. International variations in hip fracture probabilities: implications for risk assessment. J Bone Miner Res. 2002;17:1237-1244.

14. Kim BT, Mosekilde L, Duan Y, Zhang XZ, Tornvig L, Thomsen JS, Seeman E. The structural and hormonal basis of sex differences in peak appendicular bone strength in rats. $J$ Bone Miner Res. 2003;18:150-155.

15. Kim SH, Szabo RM, Marder RA. Epidemiology of humerus fractures in the United States: nationwide emergency department sample, 2008. Arthritis Care Res. 2012;64:407-414.

16. Looker AC, Beck TJ, Orwoll ES. Does body size account for gender differences in femur bone density and geometry? J Bone Miner Res. 2001;16:1291-1299.

17. Milgrom C, Giladi M, Simkin M, Rand N, Kedem R, Kashtan H, Stein M, Gomori M. The area moment of inertia of the tibia: a risk factor for stress fractures. J Biomech. 1989;22:1243-1248.

18. Riggs BL, Melton LJ, Robb RA, Camp JJ, Atkinson EJ, Peterson JM, Rouleau PA, McCollough CH, Bouxsein ML, Khosla S. Population-based study of age and sex differences in bone volumetric density, size, geometry, and structure at different skeletal sites. J Bone Miner Res. 2004;19:1945-1954.

19. Ruff CB, Hayes WC. Sex differences in age-related remodeling of the femur and tibia. J Orthop Res. 1988;6:886-896.

20. Schlecht SH, Bigelow EMR, Jepsen KJ. Mapping the natural variation in whole bone stifness and strength across skeletal sites. Bone. 2014;67:15-22.

21. Schlecht SH, Jepsen KJ. Functional integration of skeletal traits: an intraskeletal assessment of bone size, mineralization, and volume covariance. Bone. 2013;56:127-138.

22. Seeman E. From density to structure: growing up and growing old on the surfaces of bone. J Bone Miner Res. 1997;12:509-521.

23. Seeman E. Growth in bone mass and size-are racial and gender differences in bone mineral density more apparent than real? $J$ Clin Endocrinol Metab. 1998;83:1414-1419.

24. Seeman E. Sexual dimorphism in skeletal size, density, and strength. J Clin Endocrinol Metab. 2001;86:4576-4584. 